\title{
Instrução, poder e hierarquia: índices de alfabetização entre os potentados locais em Minas colonial
}

\author{
Education, power and hierarchy: literacy rates among local potentates in colonial Minas
}

Educación, podery jerarquía: las tasas de alfabetización entre los potentados locales en

Minas colonial

\section{Resumo}

Na investigação do perfil dos grupos que formavam as elites no período colonial na América portuguesa, um aspecto recentemente tem chamado a atenção dos historiadores, a saber, as taxas de alfabetização. Nesse sentido, o presente texto objetiva analisar a constância, ou não, de tal índice entre os potentados locais na comarca de Vila Rica, em Minas Gerais, na primeira metade do século XVIII. O que se busca constatar é se a alfabetização era um recurso social ou uma estratégia utilizada por tais homens em ações nas quais procuravam obter ascensão e prestígio e se, consequentemente, sua presença interferia no sucesso na busca por melhores oportunidades na capitania mineira.

Palavras-chave: Alfabetização. Potentados locais. Ascensão social.

Ana Paula Pereira Costa*

No Brasil, nas últimas décadas, a historiografia sobre o período colonial tem dedicado especial atenção para a investigação dos indivíduos e grupos que faziam parte do quadro de suas elites. Nesses estudos, com enfoques referenciais teóricos e metodologias diversas, uma das preocupações primordiais é desvendar os mecanismos de ascensão e manutenção do poder (local ou imperial) desses grupos, sublinhando-se suas estratégias para tanto. Dentre os elementos chaves para se entender o perfil desses homens e os mecanismos que dispunham para se inserirem de forma privilegiada no território da

* Doutora em História Social pela UFRJ. Professora da Universidade Federal dos Vales do Jequitinhonha e Mucuri - UFVJM.

Recebido em 29/09/2014 - Aprovado em 25/02/2015 http://dx.doi.org/10.5335/hdtv.15n.1.5287 
América portuguesa, muito já se falou acerca da concessão de mercês (doações, graças régias), do ideário da conquista, do desempenho de cargos administrativos, do exercício do poder concelhio e do estabelecimento de redes e alianças sociais verticais e horizontais (de matrimônio, comerciais, clientelares, etc. $)^{1}$. Além dos elementos citados, recentemente um aspecto tem chamado a atenção dos historiadores para se incrementar essa análise, a saber, as taxas de alfabetização.

Em um contexto de busca por melhores oportunidades de vida por parte de sujeitos de variados níveis e condições sociais nas colônias do ultramar, abertas pela expansão portuguesa no Atlântico, as habilidades de ler e escrever têm sido pensadas como um recurso social ou uma estratégia utilizada por eles em ações nas quais procuravam obter ascensão e prestígio e, portanto, para seu ingresso e manutenção nos quadros da elite colonial. $\mathrm{O}$ grupo a ser analisado refere-se a indivíduos do sexo masculino que vieram para as Minas dos Cataguases, mais especificamente para a comarca de Vila Rica, na primeira metade do século XVIII, para povoá-la e organizá-la. Dessa forma, procurou-se montar e acompanhar pequenas histórias biográficas desses homens, embasadas por aquilo que a historiografia tem ressaltado como seus elementos definidores ${ }^{2}$. Nesse caso, além dos indivíduos que atuaram nas bandeiras para descoberta do ouro nas Gerais, os chamados sertanistas, entraram nessa classificação homens que se tornaram conquistadores, ou seja, que ajudaram no povoamento e na defesa da capitania; que figuravam nas listas feitas por autoridades locais em que se levantavam os nomes dos "principais moradores da localidade"; que ocuparam cargos de mando na câmara e na administração real; que adquiriram altas patentes militares e títulos importantes como o de cavaleiros de ordens militares. E, claro, complementando esse quadro dos elementos definidores de um potentado local, foram contemplados, também, os indivíduos que tinham grandes contingentes de escravos que eventualmente reuniam em torno de si para atuarem com eles como braço armado em diversas diligências, visando à construção e/ou à manutenção de seu status. Se os potentados reivindicaram a exclusividade de partilhar com a monarquia portuguesa a autoridade no além-mar, como alguns autores já argumentaram (FRAGOSO, 2010, p. 249), essa autoridade não era dada formalmente, por pergaminhos de fidalguia titular do reino ou pelo senhorio jurisdicional. Tratava-se de um mando local costumeiro. Eram indivíduos que fizeram carreira no Império português, combinando o serviço à monarquia com o exercício do poder local (FRAGOSO, 2010, p. 248-252).

Esse grupo foi inventariado a partir de dicionários, cronistas, relatos genealógicos e arrolamento de vereadores ${ }^{3}$, resultando em uma lista na qual constaram o nome de 193 potentados locais para a região e o período enfocados. Partindo então dessa lista, priorizaram-se fontes que permitissem visualizar a capacidade desses homens de assinar o próprio nome, o que pode ser um indicativo indireto da difusão das práticas de ler e escrever entre eles. Para tanto, utilizou-se uma documentação diversificada que possibilitou supor se os potentados tinham essa habilidade. Assim, buscou-se informações acerca dessa variável em fontes como habi- 
litações para ser familiar do Santo Ofício (já que um dos requisitos para solicitar tal título era saber ler e escrever), localizadas no Arquivo Nacional da Torre do Tombo (ANTT); rol de camaristas (pois na ocupação de cargos como vereador, escrivão e procurador a alfabetização era necessária) retiradas do Arquivo Histórico da Câmara Municipal de Mariana (AHCMM), do Arquivo Público Mineiro (APM) e do Memorial Histórico- Político da Câmara Municipal de Ouro Preto; documentação administrativa presente no Arquivo Histórico Ultramarino (AHU)/ Projeto Resgate - Documentação avulsa de Minas Gerais/CD-ROM, feita e assinada por tais potentados no exercício de cargos; e documentação cartorária e notarial, tais como inventários, testamentos e registros de alforrias em que constava a assinatura desses indivíduos retiradas dos Arquivos da Casa Setecentista de Mariana (CSM) e da Casa do Pilar de Ouro Preto (CPOP), $1^{\circ}$ e $2^{\circ}$ ofícios.

Desse modo, a metodologia adotada baseou-se fundamentalmente no exame da assinatura e dos sinais deixados pelos potentados na documentação citada. Contudo, vale lembrar que nem sempre o fato de saber assinar indicava alfabetização, pois era comum aprender-se somente a desenhar o próprio nome. Quando era esse o caso, a pessoa em geral apresentava grande dificuldade ao traçar seu nome, evidenciando um grande esforço em fazê-lo (FURTADO, 1999, p. 109).

O valor da assinatura para conhecimento dos níveis de alfabetização foi amplamente discutido na historiografia ${ }^{4}$. Autores como Lawrence Stone (1969, p. 98) defendem que por tal indicador é muito difícil estabelecer precisão na relação entre a capacidade de assinar o nome e a alfabetização no sentido próprio, isto é, aptidão para usar a escrita como meio de comunicação. Já para Roger Schofield, a capacidade de assinar pode ser considerada "um indicador da alfabetização intermediário entre o domínio da escrita e o domínio da leitura" (1968, p. 524). Em artigo no qual procurou analisar a alfabetização no Porto no Antigo Regime, Francisco Ribeiro da Silva buscou detectar pela assinatura indivíduos que possuíam grande destreza e hábito de escrever e os que, igualmente capazes, tinham de se esforçar um pouco mais para assinar (1986, p. 110). Assim, Silva, afirma que é mais seguro para a análise dessa variável a distinção fundamental entre os que assinavam, ainda que de modo menos perfeito, e aqueles cuja assinatura era tão tosca, às vezes inacabada e tão mal desenhada, que a sua configuração pode ser pensada como a transição "entre as não assinaturas e as assinaturas perfeitas" (SILVA, 1986, p. 111).

Desde os primórdios da descoberta das minas do ouro, essa se constituiu como uma região de fronteira, isto é, como uma região exploratória, de conquista, que abriu novas oportunidades econômicas e de mando para empreendedores particulares que se dispuseram a utilizar seus próprios recursos materiais (e nisso se incluíam homens, armamentos e mantimentos) e suas vidas para prestar serviços ao império lusitano com a promessa de remuneração e mercês (CAMPOS, 2005, p. 342). Com efeito, por meio das expedições ou bandeiras para descoberta do ouro nas Minas Gerais, os homens, os melhores homens, puderam alargar seu cabedal político, econômico e simbólico, mudar de "qualida-

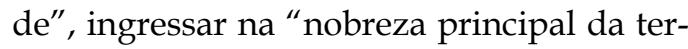


ra" e, consequentemente, mandar em outros homens e mulheres (FRAGOSO; BICALHO; GOUVÊA, 2001, p. 24). No ultramar, esta qualidade de nobreza não estava associada ao ilustre nascimento, ao sangue e à hereditariedade, mas sim, a um ideal que invocava a concepção de "nobreza civil ou política". Essa era composta por homens que, embora de nascimento humilde, conquistaram um grau de enobrecimento devido a ações valorosas que obraram ou a cargos honrosos que ocuparam (MONTEIRO, 1998, p. 298-299). Além disso, tal qualidade de nobreza evocava também um caráter guerreiro, atrelado à noção de conquistador ${ }^{5}$.

Desse modo, embrenhados nas florestas e nas trilhas dos sertões, os aventureiros do metal buscavam enriquecimento imediato, mas também se mostravam cada vez mais ávidos por recompensas (mercês reais) que vinham sob a forma de títulos, honrarias e postos militares, no intuito de conseguirem poder ou prestígio, tornando-se verdadeiros potentados locais. Temos assim, um panorama no qual, por um lado, se consolidava um processo de viabilização e manutenção da governabilidade régia nesse domínio do Império português e, por outro, se viabilizava a formação e o fortalecimento de grupos detentores de poder com os quais a coroa precisava negociar e dividir sua autoridade.

É nesse cenário, marcado por definições de hierarquias, territórios de mando, tumultos e conflitos, que as habilidades de ler e escrever se inseriam como importantes mecanismos de distinção para aqueles que objetivavam incrementar a "qualidade" social, pois, para conseguirem alcançar e se manterem nos maiores patamares, tudo que pudes- sem utilizar como diferencial era válido. Não pretendemos fazer uma história da educação ou das práticas de leitura e escrita na sociedade colonial ${ }^{6}$. O que gostaríamos de ressaltar é a presença ou não de índices de alfabetização entre os indivíduos que se constituíram em potentados locais na comarca de Vila Rica em Minas Gerais, na primeira metade do século XVIII, e como isso se transformou em um recurso ou estratégia para tais sujeitos em sua busca por ascensão e prestígio social nesta parte da América portuguesa.

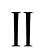

Mesmo não tendo a intenção de aprofundar discussões sobre a educação no período colonial, até porque a falta de dados não nos permite, invariavelmente alguns pontos atrelados a essa temática serão aqui destacados para embasar algumas hipóteses. Conforme salientou Renata Bezerra de Freitas Barbosa, a historiografia que por décadas foi produzida sobre a história da educação durante o período colonial colocou o letramento como apanágio das elites e enfatizou o quão diminuta era a quantidade de pessoas que sabiam ler e escrever em terras luso-americanas. Apenas recentemente os estudos sobre a educação no período colonial têm avançado, passando a contemplar tanto a educação de natureza escolar como a não escolar, presentes nas práticas sociais e culturais cotidianas (BARBOSA, 2013, p. 7).

Em artigo no qual procurou apresentar um balanço da historiografia da educação na América portuguesa, Thais Nivia de Lima e Fonseca ressaltou que a educação no Brasil, no período colonial, não pode ser limitada 
em termos de escolarização formal e, sobretudo, pública, em qualquer nível de ensino. É necessário ampliar esse entendimento, pois havia processos educativos mais amplos que, realizados intencionalmente ou não, implicavam no estabelecimento de relações nas quais alguma forma de saber circulava e era apropriado por diferentes camadas sociais, principalmente os chamados grupos subalternos (os brancos livres pobres, os indígenas, os negros livres e escravo, e a população mestiça) (FONSECA, 2009, p. 117-118). Nessa mesma linha, argumentou Luiz Carlos Villalta ao ressaltar que foram múltiplos os lugares da educação na América portuguesa. Analisando-a entre as camadas sociais mais baixas, o referido autor afirmou que se difundiu entre essas o aprender fazendo:
[...] extramuros da escola, na luta pela sobrevivência, adquiriram os rudimentos necessários para garantir a subsistência e para reproduzir os papéis que lhes eram reservados na sociedade (1997, p. 333).

De todo modo, a alfabetização na sociedade colonial distribuía-se em conformidade com as hierarquias sociais: razoavelmente disseminada entre os homens brancos livres, fazia-se menos presente entre as mulheres do mesmo grupo, sendo rarefeita entre negros e mulatos, forros e escravos (VILLALTA, 2007, p. 296).

Vejamos, então, a proporção de alfabetizados entre os potentados locais investigados, relacionando essa variável com sua naturalidade:

Tabela 1: Taxas de alfabetização entre os potentados locais, relacionadas com sua naturalidade

\begin{tabular}{|c|c|c|}
\hline Naturalidade & Número & Porcentagem \\
\hline \multicolumn{3}{|l|}{ Paulista } \\
\hline Alfabetizado & 21 & 40,4 \\
\hline Sem identificação & 31 & 59,6 \\
\hline Subtotal & 52 & 100 \\
\hline \multicolumn{3}{|l|}{ Português } \\
\hline Alfabetizado & 44 & 81,5 \\
\hline Sem identificação & 10 & 18,5 \\
\hline Subtotal & 54 & 100 \\
\hline \multicolumn{3}{|l|}{ Outras localidades } \\
\hline Alfabetizado & 6 & 66,7 \\
\hline Sem identificação & 3 & 33,3 \\
\hline Subtotal & 9 & 100 \\
\hline \multicolumn{3}{|l|}{ Naturalidade não identificada } \\
\hline Alfabetizado & 21 & 11 \\
\hline Casos com naturalidade e taxa de alfabetização desconhecida & 57 & 30 \\
\hline Total & 193 & 100 \\
\hline \multicolumn{3}{|c|}{$\begin{array}{ll}\text { Fonte: } & \text { Arquivo Nacional da Torre do Tombo (ANTT) - Habilitaçães para o Santo Ofício. Arquivo Histórico Ultramarino (AHU)/Projetc } \\
\text { Resgate - Documentação Avulsa de Minas Gerais/CD-ROM. Acórdãos do Arquivo Histórico da Câmara Municipal de Mariana } \\
\text { (AHCMM). Arquivo Público Mineiro (APM), Seção Colonial - Cód. 02, } 05 \text { e } 06 \text {. Memorial Histórico-Político da Câmara Municipal de } \\
\text { Ouro Preto. Ouro Preto: Cor \& Cor Editorial, dez. 2004. Inventários post-mortem e testamentos da Casa Setecentista de Mariana } \\
\text { (CSM) e da Casa do Pilar de Ouro Preto (CPOP), } 1^{\circ} \text { e } 2^{\circ} \text { ofícios. Escrituras de alforria e liberdade dos livros de Notas do } 1^{\circ} \text { e } 2 \\
\text { Ofícios da CSM e da CPOP. }\end{array}$} \\
\hline
\end{tabular}


Pela Tabela 1, percebe-se que era relativamente alto o índice de alfabetização entre os potentados. Constata-se que dentre os 193 nomes listados, 48,2\% (93 casos) eram alfabetizados, porcentagem que poderia ser maior, visto que para 51,8\% não conseguimos obter esse dado, não podemos afirmar que eram analfabetos. Para cerca de 30\% (57 casos) dos nomes investigados não conseguimos registros tanto sobre a origem, quanto sobre a alfabetização e em $11 \%$, sabemos apenas que eram indivíduos alfabetizados, mas não conhecemos a naturalidade (21 casos). Ao relacionarmos as taxas de alfabetização com a origem dos potentados, visualiza-se o seguinte resultado: dentre os 52 paulistas arrolados 40,4\% eram alfabetizados e para 59,6\% não nos foi possível obter informações acerca dessa variável. Já entre os 54 portugueses listados 81,5\% tinham a habilidade de ler e escrever e para $18,5 \%$ não conseguimos averiguar tal tipo de informação. Para os nove potentados provenientes de outras localidades da América portuguesa (seis eram naturais do Rio de Janeiro, um de Pernambuco, um da Bahia e um de Minas Gerais), 66,7\% sabiam ler e escrever (três casos do Rio de Janeiro e os casos de Pernambuco, Bahia e Minas Gerais) e para
33,3\% não conseguimos ter notícias sobre tal habilidade (três casos do Rio de Janeiro).

Nota-se que estava entre os portugueses os maiores índices dessa variável, o que ratifica alguns resultados encontrados pela historiografia que recentemente tem incluído esse item em suas análises acerca da formação da elite colonial ${ }^{7}$. Não é novidade que, durante o século XVIII, a capitania de Minas Gerais recebeu número considerável de portugueses, vindos para o exercício de postos na administração civil e militar e como membros do clero, ou atraídos pelas possibilidades, reais ou imaginadas, de enriquecimento na economia mineradora, e que jamais retornaram ao reino (FONSECA, 2008, p. 1). Como bem ressaltou Thais Nivia de Lima e Fonseca, não obstante as divergências entre os historiadores, no Brasil e em Portugal, quanto à quantidade de portugueses vindos para a América, não parece haver dúvidas quanto ao aumento dessa imigração no século XVIII, movida, principalmente, pela exploração do ouro nas Minas Gerais, e quanto ao fato de que a maioria dos emigrados provinha do norte de Portugal (FONSECA, 2008, p. 1) ${ }^{8}$. Esse também parece ter sido o caso do grupo de potentados por nós analisado.

Tabela 2: Regiões de Portugal das quais eram provenientes os potentados locais de origem portuguesa

\begin{tabular}{l|c|c}
\hline \multicolumn{1}{c|}{ Região de Portugal } & Número & Porcentagem \\
\hline Norte e Centro Norte (Minho, Douro, Trás-os-Montes e Beira) & 26 & 48,1 \\
Estremadura e Alentejo & 15 & 27,8 \\
Sem identificação & 13 & 24,1 \\
Total & 54 & 100 \\
\hline
\end{tabular}

Fonte: Arquivo Nacional da Torre do Tombo (ANTT) - Habilitações para o Santo Ofício. Arquivo Histórico Ultramarino (AHU)/Projeto Resgate - Documentação Avulsa de Minas Gerais/CD-ROM. Acórdãos do Arquivo Histórico da Câmara Municipal de Mariana (AHCMM). Arquivo Público Mineiro (APM), Seção Colonial - Cód. 02, 05 e 06. Memorial Histórico-Político da Câmara Municipal de Ouro Preto. Ouro Preto: Cor \& Cor Editorial, dez. 2004. Inventários post-mortem e Testamentos da Casa Setecentista de Mariana (CSM) e da Casa do Pilar de Ouro Preto (CPOP), $1^{\circ}$ e $2^{\circ}$ ofício. Escrituras de Alforria e Liberdade dos Livros de Notas do $1^{\circ}$ e $2^{\circ}$ Ofício da CSM e da CPOP. 
Com base na Tabela 2, verifica-se que, dos 54 portugueses encontrados na amostragem, $48,1 \%$ eram provenientes das regiões Norte e Centro Norte (Minho, Douro, Trás-os-Montes e Beira) e 27,8\% das regiões da Estremadura e Alentejo. Para $24,1 \%$ dos indivíduos pesquisados não se conseguiu obter essa identificação. Os dados descritos tendem a confirmar algumas hipóteses sobre a emigração portuguesa para a América lusa no período colonial, que estão sendo trabalhadas pela historiografia, dentre essas o argumento de que havia um investimento familiar no preparo dos jovens oriundos, sobretudo, do norte de Portugal que emigraram para o domínio ultramarino. Ao analisar a caracterização global dos modos de governar da monarquia portuguesa na segunda metade dos setecentos, com uma ênfase especial na política atlântica, traçando, para tanto, uma breve investigação acerca do perfil dos portugueses que emigravam para a América portuguesa, Nuno Gonçalo Monteiro destacou um retrato bem próximo ao encontrado por nossa pesquisa e por vários estudiosos que também se debruçaram sobre esta temática. Segundo esse autor, a emigração "espontânea" portuguesa (não organizada pela Coroa) tinha, sobretudo, origem no norte de Portugal, particularmente no Minho (que fornecia em norma mais da metade dos migrantes), seguida pelas ilhas e por zonas do centro do reino e de Lisboa. Era uma emigração majoritariamente jovem, masculina e, ao que tudo indica, alfabetizada, que se inseria em grande medida dentro de uma lógica de expulsão de filhos excedentários de grupos domésticos de lavradores razoavelmente abastados do nordeste, a zona agrícola mais rica e densamente povoada de Portugal, e também de filhos de artesãos. Uma emigração de remediados, portanto, dotados de dois capitais extremamente valiosos: saber ler e escrever, num país esmagadoramente analfabeto, e um espectro de relações que lhes garantiam uma colocação conveniente no local quase sempre urbano de destino (MONTEIRO, 2009, p. 77).

Segundo Fonseca (2008), muitas pesquisas recentes comprovam a entrada e o uso da cultura escrita como mecanismo de inserção social na capitania de Minas Gerais. Muitos viviam de ofícios que exigiam esse conhecimento. Afinal, era no âmbito da escrita que boa parte das relações cotidianas se realizavam: entre os indivíduos e as instâncias administrativas civis, eclesiásticas ou militares; entre eles e a justiça; entre os indivíduos uns com os outros, em suas atividades ligadas ao comércio, à mineração, ao exercício de variados ofícios e profissões. Desse modo, emigrantes, e muitas vezes também seus descendentes, estabeleceram relações com a cultura escrita que resultaram na resolução de seus problemas e no registro de parte de suas trajetórias, no estabelecimento de estratégias para a educação de seus filhos, no incremento da circulação de livros, no ensino das primeiras letras e da gramática latina (2008, p. 1 e 4).

De acordo com essa mesma autora, no momento da emigração para as Minas Gerais no século XVIII, a sociedade portuguesa já vivia transformações no sentido da expansão da cultura escrita, com o aumento da publicação e circulação de livros, a ampliação da burocracia estatal que exigia cada vez mais pessoas com algum letramento, e o 
ingresso de uma parte da população dos domínios ultramarinos na estrutura administrativa e educacional do Império português. Nas palavras de Fonseca:

Não obstante o grande peso da cultura oral, é fato aceito por diversos historiadores que tais transformações, desde o século $\mathrm{XV}$, foram progressivamente introduzindo parcelas maiores da população na cultura escrita, mesmo sem o correspondente aumento da escolarização. $\mathrm{O}$ desenvolvimento das atividades comerciais, por exemplo, exigiu cada vez mais o recurso ao registro escrito, e a "palavra escrita" passava a ganhar novo valor social (2008, p. 5-6).

Nuno Gonçalo Monteiro (2009), Jorge Pedreira (2001), Júnia Furtado (1999), de Lima (2008), Carla Maria Carvalho de Almei$\mathrm{da}^{13}$, entre outros, reconheceram ou demonstraram em seus trabalhos que o comércio foi uma das atividades a que os portugueses oriundos da Região Norte e instalados nas Minas do século XVIII se dedicaram recorrentemente. No trato mercantil, a cultura escrita era crucial para o bom desempenho das atividades servindo para comprovar, por exemplo, registro de empréstimos, recibos de pedidos de mercadorias, reconhecimento de dívidas, registro de movimentos comerciais, etc. Como demonstrou Júnia Furtado, nas Minas, onde a escassez de moedas e proibição de circulação de ouro em pó impuseram a proliferação de um sistema de empréstimo baseado em recibos e letras de crédito, a palavra escrita tornou-se muito importante, e, em especial, a escrituração comercial (1999, p. 107). Além disso, as habilidades de ler e escrever, o domínio da informação nessa sociedade eram vitais não só para o bom desempenho dos negócios, como para se ter notícias dos familiares e colocar-se a par de diversos assuntos e, acima de tudo, era forma de demonstrar poder e afirmar-se perante os outros (FURTADO, 1999, p. 106).

A título de ilustração, destacaremos dois casos emblemáticos dentro desse grupo de 193 potentados analisados no seio do qual ser alfabetizado fez toda a diferença para o sucesso em busca por ascensão e prestígio social na capitania mineira. Trata-se dos portugueses Bento Ferraz Lima e Custódio Rebelo Vieira.

Bento Ferraz Lima bem jovem, com aproximadamente 15 anos, deixou a casa de seus pais, na freguesia de São João da Ribeira, termo da vila de Ponte de Lima, arcebispado de Braga, rumo ao Brasil. Era de família humilde. Seu pai, João Rodrigues, tinha o ofício de sapateiro, e sua mãe, Maria Ferraz, "antes de casar estivera por criada de servir nessa freguesia 30 anos em casa de Bento da Costa Tição (sic) e lhe fazia de comer, e depois de casada se tornou tecedeira" (ANTT. Habilitação da Ordem de Cristo de Bento Ferraz Lima. Letra B, Maço11, doc. 6. maio de 1740). Mesmo tendo uma modesta origem social, Bento Ferraz Lima foi alfabetizado por seu pai durante o tempo em que permaneceu em sua terra natal, pois " assistira sempre em companhia de seus pais a estudar e a aprender a ler e a guardar as ovelhas de seu pai". Além disso, "trabalhou nesta corte na rua do escudeiro por caixeiro do mercador Leandro Nunes Colhares lhe assistindo perto de um ano antes de se embarcar para as minas" (ANTT. Habilitação da Ordem de Cristo de Bento Ferraz Lima. Letra B, Maço 11, doc. 6. maio de 1740), o que sem dúvida o ajudou a exercitar o letramento. 
O fato de Bento Ferraz Lima ter uma origem humilde, habitar uma localidade rural e, portanto, não ter acesso direto a uma escolarização formal/institucional, não foi impedimento para que conseguisse ser alfabetizado. A preocupação de seu pai em lhe ensinar a leitura e a escrita mostra a tentativa de prepará-lo para o trabalho, com o intuito de garantir sua sobrevivência. Habilidades essas que certamente foram ainda mais apuradas quando exerceu o ofício de caixeiro, no reino e no ultramar, já que ao embarcar para a América portuguesa estabeleceu-se primeiro na Bahia onde "trabalhou como caixeiro de um mercador de loja aberta na rua dos douradores, e depois foi para as minas donde serve de minerar" (ANTT. Habilitação da Ordem de Cristo de Bento Ferraz Lima. Letra B, Maço 11, doc. 6. maio de 1740).

Casos como esse, nos quais emigrantes portugueses buscavam aprender ou aprimorar a leitura e a escrita juntamente com o exercício de algum ofício, não eram raros entre o grupo ora enfocado. Nem mesmo entre indivíduos de outras procedências que habitavam a América portuguesa como aponta, por exemplo, Luiz Carlos Villalta. Esse autor destacou que a educação do "aprender fazendo" a que muitos sujeitos tinham acesso no território colonial se apresentava em vínculos informais como os que envolviam a relação entre mestres e aprendizes para o aprendizado de ofícios e das primeiras letras. Segundo Villalta, entre os letrados da colônia, muitos teriam se formado assim, nessa relação mestre-aprendiz, juntamente com o aprendizado de seus ofícios (VILLALTA, 1997, p. 357; BARBOSA, 2013, p. 8).
Seja como for, o importante a destacar é que a instrução foi para muitos desses homens um recurso acionado e valorizado em sua busca por melhores oportunidades no além-mar. Por meio de um domínio maior ou menor da leitura e da escrita podiam circular em diversas instâncias sociais e assim ascender. Não por acaso, Bento Ferraz Lima, já nas Minas, fixou-se na freguesia de Catas Altas, tornando-se, nessa localidade, homem de muitas posses. Atuou como minerador, senhor de engenho, sendo ainda um grande proprietário de escravos ${ }^{9}$. Política e socialmente conseguiu também posição proeminente. Tornou-se sargento-mor e capitão-mor de ordenanças em Catas Altas (AHU/ MG/cx.:29; doc.:77), ocupou os cargos de vereador em 1720 e de juiz almotacé em 1721 na câmara da Vila do Carmo (Acórdãos da Câmara Municipal de Mariana. APM. Seção Colonial - Cód. 02, 05 e 06) e tornou-se cavaleiro da Ordem de Cristo (ANTT. Habilitação da Ordem de Cristo de Bento Ferraz Lima. Letra B, Maço 11, doc. 6. maio de 1740), pedindo ainda o título de familiar do Santo Ofício (ANTT. Familiatura do Santo Ofício de Bento Ferraz Lima. Incompleta, maço 23, doc. 925. Janeiro de 1730). Em sua habilitação para ser familiar do Santo Ofício, título em que o requisito "saber ler e escrever" era altamente destacado. Era apontado como homem de boa reputação, - não obstante, os boatos que existiam sobre ter uma filha ilegítima "com uma mulata forra de nome Thereza de Barros porque tem por ela muito recolhimento e estimação" (ANTT. Familiatura do Santo Ofício de Bento Ferraz Lima. Incompleta, maço 23, doc. 925. janeiro de 1730). Segundo o processo: 
Bento Ferraz Lima tem bom procedimento, vida e costumes, vive limpa e abastadamente de minerar, de seu engenho de cana, e possui cento e tantos escravos donde tiradas suas dividas terá de seu trinta mil cruzados para cima, sabe ler e escrever, representa ter de idade de 30 para 40 anos. Nunca foi casado até o presente sempre foi conhecido por solteiro, tem em sua casa uma menina filha de mulata que vulgarmente se dizem ser sua filha. Sempre foi tido por legitimo cristão velho sem notícia de que tenha sido preso por infâmia (ANTT. Familiatura do Santo Ofício de Bento Ferraz Lima. Incompleta, Maço 23, doc. 925. janeiro de 1730).

Pode-se dizer, dessa maneira, que em todas as etapas de seu bem sucedido percurso o fato de saber ler e escrever foi um recurso ou facilitador de sua entrada em alguns círculos sociais privilegiados nos quais esse requisito era exigido, como no caso da familiatura do Santo Ofício e no exercício de cargos públicos, bem como um importante diferenciador na condução de seus negócios pessoais.

Temos outro exemplo na trajetória de Custódio Rebelo Vieira. Esse reinol, natural da freguesia de São Julião de Tobalos, era filho natural do Dr. Leonardo Leite Rebello e de Maria Vieira. Migrou bem jovem para a América portuguesa, instalando-se, inicialmente, no Rio de Janeiro. Pelo fato de ser alfabetizado pôde trabalhar como caixeiro nessa cidade, ofício que muitos outros potentados reinóis do grupo analisado também exerceram antes de se tornarem homens de prestígio e autoridade nas Minas, o que o exemplo de Bento Ferraz Lima já mencionado também demonstrou. No seu processo de habilitação para entrar na Ordem de Cristo tem-se descrito que: "passando deste reino para o Brasil executara no Rio de Janeiro a ocupação de caixeiro no trapiche do Dr. João da Motta Leite cobrando o salário que se costuma dar a semelhantes caixeiros" (ANTT. Habilitação da Ordem de Cristo de Custódio Rebelo Vieira. Letra C, Maço 11, doc. 15. março de 1729). $\mathrm{Na}$ tentativa de demonstrar que tal ofício não devia ser encarado como defeito mecânico e, portanto, como impedimento para entrar na ordem, Custódio Rebelo Vieira esclareceu que:

Caixeiro era como as em que vulgarmente chamam neste reino caixeiro de loja que induz mecânica pessoal pelo exercício de venderem publicamente em tendas ou lojas e o dito tribunal deu conta a V. Mag. de que o suplicante tinha mecânica pessoal na qual tinha incorrido por ter exercitado a dita ocupação de caixeiro e por que o suplicante quer mostrar que a ocupação de caixeiro no dito trapiche é nobre e não tem exercício nenhum que possa por si induzir mecânica, pois não é daquelas caixarias de que se usa neste reino. É somente um administrador de todos os açucares dos engenhos daquele distrito que tem na dita administração o ser como juiz e fiel daquela balança por cujas estão obrigados os senhores de engenhos a dar inteira fé e credito a certidão do peso que passar o dito caixeiro do trapiche cujo nome lhe dão os naturais não porque na realidade sejam caixeiros como os mais a que se dá este nome mas por respeitar o seu maior exercício de assistir como juiz e fiel da balança ao peso de todas as caixas de açúcar daquele distrito de sorte que sendo a propriedade deste oficio do Visconde de Asseca ninguém devia ser ele ou algum de seus filhos a exercitasse que perderia por isso a sua nobreza além de que o nome vulgar que tem no Rio de Janeiro esta ocupação não é simplesmente de caixeiro, mas de caixeiro mor do trapiche do Motta por ser entre os naturais reputada por das melhores e mais autorizadas (ANTT. Habilitação da Ordem de Cristo de Custódio Rebelo Vieira. Letra C, Maço 11, doc. 15. março de 1729). 
$\mathrm{Na}$ sua argumentação percebe-se o quanto o fato de ser alfabetizado foi um recurso fundamental para o exercício deste ofício e acionado para demonstrar diferenciação e "nobreza" de sua parte, pois se tratava de "um administrador de todos os açúcares dos engenhos daquele distrito que tem na dita administração o ser como juiz e fiel daquela balança". No seu ponto de vista não devia ser classificado como um simples caixeiro, mas como "caixeiro mor do trapiche do Motta por ser, entre os naturais, reputada por das melhores e mais autorizadas". Nessa sociedade marcada por valores de honra, status e nobreza, era fundamental que o sujeito esclarecesse e tivesse aceita sua "qualidade" social, sobretudo nesse caso no qual o agraciamento com um título que incrementaria tal "qualidade" estava em jogo e que só era concedido àqueles homens suficientemente nobilitados para tanto. Desse modo, o fato de ter exercido um ofício mecânico podia, teoricamente, se tornar um enorme obstáculo para Custódio Rebelo Vieira confirmar sua posição social. Contudo, cabe aqui uma ressalva.

De acordo com Renata Bezerra de Freitas Barbosa vários estudos, por muito tempo, ao tratarem da valoração do trabalho manual na América portuguesa - assim como do papel social de seus agentes - argumentaram o quanto, durante o período colonial, os ofícios mecânicos estiveram envoltos em um significado aviltante, desqualificador. Tal significado, somado ao fato de ser esta, no período, uma sociedade escravocrata e ávida por honras e mercês, teria estimulado os mecânicos ao abandono de seus ofícios na primeira oportunidade de ascensão social
(2013, p. 1). Dessa maneira, segundo esse ponto de vista, o trabalho encarado como "defeito mecânico" teria figurado na América portuguesa - bem como no reino e em outras partes do Império português - como fator impeditivo para obtenção de cargos importantes ou honrarias.

Todavia, recentemente algumas pesquisas vêm relativizando essa assertiva, mostrando um caminho mais amplo de interpretação sobre a valoração do trabalho manual e sobre o papel social dos oficiais mecânicos nos setecentos. Assim, algumas investigações acerca do trabalho manual na América portuguesa - ou que se debruçaram de alguma forma sobre os seus agentes - têm apontado não só uma complexidade em sua composição social, mas também relativizado a valoração negativa atribuída aos trabalhadores manuais, mostrando a circularidade de muitos oficiais mecânicos em esferas sociais diversas (BARBOSA, 2013, p. 5-6).

Como exemplo podemos citar a pesquisa de mestrado, em andamento, de Renata Bezerra de Freitas Barbosa na qual procura perceber as transformações ocorridas no século XVIII em relação à valoração do trabalho manual, tomando como estudo de caso a Irmandade do Patriarca São José, fundada por oficiais mecânicos por volta de 1735, na vila do Recife. A referida autora questiona o grau de envilecimento social que o exercício de ofícios mecânicos proporcionaria, de fato, aos seus agentes, bem como a condição, usualmente difundida, de terem de abandonar - pelo menos teoricamente - seus ofícios para que pudessem ascender socialmente. Segundo Barbosa, havia entre os oficiais mecânicos uma maior ou menor circulação em 
meios sociais mais "privilegiados" graças a alguns facilitadores, tais como, a prestação de serviços à Coroa e o enriquecimento. Existiam outros, como o casamento, a formação de laços importantes de parentesco, a ordenação clerical e o letramento. Nesse último foca maior atenção para tentar mostrar o quanto, no período colonial, os oficiais mecânicos estavam inseridos cotidianamente na cultura escrita e como, a partir de um domínio significativo, ou não, da leitura e da escrita, tinham maiores ou menores chances de ascensão (BARBOSA, 2013, p. 2-7).

Essas premissas talvez ajudem a entender por que Custódio Rebelo Vieira continuou a se dedicar ao trabalho manual ao longo de sua vida, arriscando ter "problemas" em sua busca por ascensão social. Foi o que constatamos em seu processo para habilitação para a Ordem de Cristo no qual revelou que ao migrar do Rio de Janeiro para as Minas passou a se dedicar a um novo negócio, no caso, conduzir fazendas secas e molhadas. Segundo consta no documento:

Passou do Rio de Janeiro para Minas Gerais com uma carregação de fazendas secas e molhadas, comprando pretos no Rio de Janeiro e Bahia para os vender nas Minas, e neste exercício continuou alguns anos vindo da dita cidade e Bahia a fazer carregações suas e de outras pessoas que ou com ele tinha companhia nelas ou the davam sua comissão para o ajuste dos comboios e vender nas Minas onde vendia em partidas por aqueles distritos e no de Vila Rica (ANTT. Habilitação da Ordem de Cristo de Custódio Rebelo Vieira. Letra C, Maço 11, doc. 15. março de 1729).

Posteriormente:
Abriu loja de fazenda secas cuja varejava pela sua mão na mesma loja em que a estava vendendo pessoalmente a fazenda dela e ultimamente teve lavras em que tirou ouro por seus escravos no Ribeirão do Carmo no sitio de mata cavalos aonde tem ainda um domicilio e daí veio por Pernambuco a esta corte em que se acha sem ocupação alguma (ANTT. Habilitação da Ordem de Cristo de Custódio Rebelo Vieira. Letra C, Maço 11, doc. 15. março de 1729).

Muito provavelmente, o ofício no trapiche fluminense o ajudou a adquirir experiência e meios materiais para conduzir essa nova atividade nas Minas. Além disso, podemos considerar que no desempenho dos dois negócios a que esse potentado se dedicou, a habilidade de ler e escrever e a sua prática como caixeiro foram muito proveitosas, pois lhe deram vantagens sobre outros comerciantes que não tinham essas aptidões servindo, por exemplo, para elaboração dos cálculos mercantis, escrituração de livros, entendimento de diferenças cambiais, de pesos e medidas e, neste sentido, para ter uma melhor atuação no mercado. Por isso, a alfabetização constituiu-se para muitos potentados em um recurso social de grande importância para o sucesso de suas trajetórias em busca de melhores oportunidades no além-mar. No caso de Custódio Rebelo Vieira, podemos pensar que essa habilidade facilitou não só seu enriquecimento, mas também a conquista de destaque social. Mesmo lhe tendo sido negada a concessão de seu hábito da Ordem de Cristo pela Mesa de Consciência e de Ordens, devemos considerar que ele conseguiu assegurar uma imagem de potentado na localidade em que se inseria. A Mesa de Consciência e Ordens 
era a instituição que administrava a concessão de hábitos de ordens militares (Santiago, Avis e Cristo) cuja aquisição implicava ser aprovado em uma série de exigências baseadas em estatutos e em várias provanças de isenção de defeito "mecânico" e limpeza de sangue que até a segunda metade do século XVIII permaneceram muito rígidas (SILVA, 2004, p. 98-106).

A negação do hábito consistiu-se nos seguintes pressupostos, segundo parecer da Mesa:

Consta que o suplicante é filho natural e que no princípio foi caixeiro no Rio de Janeiro cobrando salário e depois foi comissário (sic) de fazendas secas que levava para as minas e ultimamente vivera de minerar por seus escravos e por tais impedimentos o julgamos não estar capaz de entrar na ordem (ANTT. Habilitação da Ordem de Cristo de Custódio Rebelo Vieira. Letra C, Maço 11, doc. 15. março de 1729).

Entretanto, foram esses mesmos pressupostos, além do fato de saber ler e escrever, que se constituíram em diferenciais para Custódio Rebelo Vieira na aquisição de cargos políticos e patentes militares nas Minas que lhe proporcionaram destaque social. $\mathrm{O}$ referido potentado atuou, por dezoito anos, no posto de capitão de cavalos em uma companhia de ordenanças, bem como no cargo de provedor dos quintos com muito "zelo, valor e muito dispêndio de sua fazenda" (AHU/MG cx.: 39, doc.: 4). Para a ocupação dos mencionados posto e cargo, sobretudo o de provedor, ter algum domínio sobre a leitura e escrita era essencial e fazia com que a aquisição deles se concentrasse em indivíduos que tivessem tais habilidades. O provedor era o responsável pelo controle e pela coleta dos quintos (imposto sobre a arrecadação do ouro em Minas Gerais cuja taxa era de $20 \%$ ) e, nesse sentido, tinha que fazer o registro de todo ouro retirado da capitania, tarefa para a qual o letramento era requisito solicitado. Além disso, os referidos posto e cargo propiciavam a seus ocupantes notoriedade e estima social ante os pares da localidade em que se inseriam, já que só eram escolhidos para eles indivíduos com cabedais, honra e "qualidade" social para tanto ${ }^{10}$.

O texto objetivou demonstrar a importância que a alfabetização teve para indivíduos que se dirigiram para a região de Minas Gerais no início de sua formação, a fim de povoá-la e organizá-la. Por meio do exercício de ofícios manuais tais como caixeiro, das atividades de minerar, do comércio, da ocupação de cargos políticos, da aquisição de patentes, os que foram para essa parte da América portuguesa conseguiram enriquecer e se nobilitar. Nesse percurso, as habilidades de ler e escrever se constituíram em um recurso diferenciador, estratégico, que aumentou as chances de sucesso nessa empreitada.

\section{Abstract}

In the investigation of the profile of the groups that formed the elite during the colonial period in Portuguese America one aspect has recently drawn the attention of historians, namely, their literacy rates. In this sense, this paper aims to examine the level of such rates among local potentates in the district of Vila Rica in Minas Gerais in the first half of the eighteenth century. What is intent to investigate is if literacy was a social resource 
or strategy used by those men in actions aimed at obtaining status and prestige and, consequently, if its presence influenced success in the search for better opportunities in the Capitania of Minas.

Keywords: Literacy. Local potentates. Social rise.

\section{Resumen}

En el perfil de investigación de los grupos que formaron las elites en el período colonial en América portuguesa un aspecto que ha llamado recientemente la atención de los historiadores, a saber, sus tasas de alfabetización. En este sentido, el presente trabajo tiene como objetivo analizar la constancia o no de dicho contenido entre los potentados locales en el distrito de Vila Rica, en Minas Gerais, en la primera mitad del siglo XVIII. Lo que se busca es visto si la alfabetización era un recurso social o estrategia usada por hombres en acciones en las que trataban de obtener auge y prestigio $y$, en consecuencia, su presencia interfiere con el éxito en la búsqueda de mejores oportunidades en la capitanía de la minería.

\section{Palabras clave: Alfabetización. Potenta-} dos locales. Ascensión social.

\section{Notas}

1 Ver: FRAGOSO, João. A formação da economia colonial no Rio de Janeiro e de sua primeira elite senhorial (séculos XVI e XVII). In: FRAGOSO, João; BICALHO, Maria Fernanda; GOUVÊA, Maria de Fátima (Org.). O Antigo Regime nos trópicos: a dinâmica imperial portuguesa (séculos XVI - XVIII). Rio de Janeiro: Civilização Brasileira, 2001. p. 29-71.; ROMEIRO, Adriana. Paulistas e Emboabas no coração das Minas. Ideias, práticas e imaginário político no século XVIII. Belo Horizonte: UFMG, 2008. 431 p.; CAMPOS, Maria Verônica. Goiás da década de 1730: pioneiros, elites locais, motins e fronteiras. In: BICALHO, Maria Fernanda.; FERLINI, Vera Lúcia do Amaral (Org.). Modos de governar. Ideias e práticas políticas no Império português, séculos XVI a XIX. São Paulo: Alameda, 2005. p. 341-359.

2 Para exemplos de estudos que trabalham na perspectiva mencionada ver: MELLO, Evaldo Cabral de. Rubro veio: o imaginário da restauração pernambucana. Rio de Janeiro: Topbooks, 1997.; FRAGOSO, João; BICALHO, Maria Fernanda; GOUVÊA, Maria de Fátima (Org.). O Antigo Regime nos trópicos: a dinâmica imperial portuguesa (séculos XVI - XVIII).; FURTADO, Júnia Ferreira (Org.). Diálogos Oceânicos. Minas Gerais e as novas abordagens para uma história do império ultramarino português. Belo Horizonte: UFMG, 2001.; FRAGOSO, João. Afogando em nomes temas e experiências em história econômica. Topoi. Revista de História. Rio de Janeiro, v. 5, p. 18-32. 2002.; FRAGOSO, João. A nobreza vive em bandos: a economia política das melhores famílias da terra do Rio de Janeiro, século XVII: algumas notas de pesquisa. Tempo. Revista do Departamento de História da UFF, Niterói, v. 15, p. 11-35. 2003.; FRAGOSO, João. Potentados coloniais e circuitos imperiais: notas sobre uma nobreza da terra, supracapitanias, no Setecentos. In: MONTEIRO, Nuno G.; CARDIM, Pedro; CUNHA, Mafalda Soares da (Org.). Optima Pars - elites ibero-americanas do Antigo Regime. Lisboa: Imprensa de Ciências Sociais, 2005.; FRAGOSO, João. À Espera das frotas: micro-história tapuia e a nobreza principal da terra (Rio de Janeiro, c.1600 - c.1750). Rio de Janeiro: UFRJ, 2005. Tese apresentada no concurso público para professor titular de Teoria da História da UFRJ; BICALHO, Maria Fernanda A cidade e o Império: o Rio de Janeiro no século XVIII. Rio de Janeiro: Civilização Brasileira, 2003.; BICALHO, Maria Fernanda. Elites coloniais: a nobreza da terra e o governo das conquistas. História e historiografia. In: MONTEIRO, Nuno G.; CARDIM, Pedro; CUNHA, Mafalda Soares da (Org.). Optima Pars - elites ibero-americanas do Antigo Regime. Lisboa: ISC - Imprensa de Ciências Sociais, 2005; BICALHO, Maria Fernanda. Conquista, mercês e poder local: a nobreza da terra na América portuguesa e a cultura política do Antigo Regime. Revista Almanack Brasiliense, n. 2, São Paulo, nov. 2005; CAMPOS, Maria verônica. Governo de mineiros. De como meter as Minas numa moenda e beber-lhe o caldo dourado. Tese (Dou- 
torado em História) - FFLCH, Universidade de São Paulo, São Paulo, 2002; CAMPOS, Maria Verônica. Goiás da década de 1730: pioneiros, elites locais, motins e fronteiras. In: BICALHO, Maria F.; FERLINI, Vera Lúcia do Amaral (Org.). Modos de governar. SILVA, Célia Nonata da. A teia da vida: violência interpessoal nas Minas setecentistas. Belo Horizonte: UFMG, 1998. Apresentado como dissertação de mestrado. FRAGOSO, João; GOUVÊA, Maria de Fátima (Org.). Na trama das redes: política e negócios no império português, séculos XVI-XVIII. Rio de Janeiro: Civilização Brasileira, 2010. FRAGOSO, João; GUEDES, Roberto \& KRAUSE, Thiago (Org.). A América portuguesa e os sistemas atlânticos na Epoca Moderna. Rio de Janeiro: FGV, 2013. ALMEIDA, Carla. Uma nobreza da terra com projeto imperial: Maximiliano de Oliveira Leite e seus aparentados. In: FRAGOSO, João; ALMEIDA, Carla; SAMPAIO, Antonio Carlos Jucá de (Org.). Conquistadores e negociantes: histórias de elites no Antigo Regime nos Trópicos. América lusa, séculos XVI a XVIII. Rio de Janeiro: Civilização Brasileira, 2007. COSTA, Ana Paula Pereira. Potentados locais e seu braço armado: as vantagens e dificuldades advindas do armamento de escravos na conquista das Minas. Topoi. Revista de História, Rio de Janeiro, v. 14, p. 18-32, 2013.

3 Neste caso recorremos a obras como: FRANCO, Francisco de Assis Carvalho. Dicionário de bandeirantes e sertanistas do Brasil. Belo Horizonte: Itatiaia; São Paulo: USP, 1989, 443 p. VASCONCELOS, Diogo de. História Antiga das Minas Gerais. Belo Horizonte, Itatiaia, 1999, 428 p. LEME, Luiz Gonzaga da Silva. Genealogia Paulistana. CD. São Paulo: Macromedia, 2002 (Organização Maria Amato). LEME, Pedro Taques de Almeida Pais. Nobiliarquia paulistana histórica e genealógica. Belo Horizonte: Itatiaia; São Paulo: Edusp, 1980. v. 3. FIGUEIREDO, Luciano R.; CAMPOS, Maria Verônica (Coord.). Códice Costa Matoso. Belo Horizonte: Fundação João Pinheiro, 1999. v. 2. Quanto às listas de vereadores, elas foram inventariadas dos Termos de Acórdãos e Vereanças, que contêm o nome dos elegíveis da Câmara de Mariana, alocados no Arquivo Público Mineiro Cód. 02, 05 e 06; e da relação dos oficiais da Câmara de Ouro Preto, desde sua fundação, retirada do Memorial Histórico-Político da Câmara Municipal de Ouro Preto. Ouro Preto: Cor \& Cor, dez. 2004.

4 Cf.:MAGALHÃES, Justino. Ler e escrever no mundo rural do Antigo Regime. Braga: Universidade do Minho, 1994, 595 p. SCHOFIELD, Roger. The measurement of literacy in pre-industrial England. In: GOODY, Jack P. (Ed.). Literacy in traditional societies. Cambridge: Cambridge University, 1968, p. 311-325. STONE, Lawrence. Literacy and education in England, 1640-1900. Past and Present, Oxford, n. 42, p. 69-139, 1969. SILVA, Francisco Ribeiro da. A alfabetização no Antigo Regime: o caso do Porto e da sua região (15801650). Revista da Faculdade de Letras, Lisboa, n. 3, p. 101-164, 1986.

5 Acerca dessa noção ver: FRAGOSO, João. A nobreza vive em bandos: a economia política das melhores famílias da terra do Rio de Janeiro, século XVII: algumas notas de pesquisa. Tempo, Niterói, v. 15, p. 11-35. 2003.

6 Para exemplos desse tipo de abordagem ver os trabalhos de: FONSECA, Thaís Nivia de Lima e. Letras, oficios e bons costumes: civilidade, ordem e sociabilidade na américa portuguesa. Belo Horizonte: Autêntica, 2009, 176 p. VILLALTA, Luiz Carlos. O que se fala e o que se lê: língua, instrução e leitura. In: SOUZA, Laura de Mello e (Org.). História da vida privada no Brasil: cotidiano e vida privada na América portuguesa. São Paulo: Cia das Letras, 1997, pp. 331-385. VILLALTA, Luiz Carlos. Ler, escrever, bibliotecas e estratificação social. In: RESENDE, Maria Efigênia Lage de; VILLALTA, Luiz Carlos (Org.). História de Minas Gerais. Belo Horizonte: Autêntica, 2007, p. 289311. v. 2.

7 Ver os trabalhos de: FURTADO, Júnia F. Homens de negócio: a interiorizarão da metrópole e do comércio nas Minas setecentistas. São Paulo: Hucitec, 1999, 289 p. PEDREIRA, Jorge. O Brasil, fronteira de Portugal. Negócio, emigração e mobilidade social (séculos XVII e XVIII). In: CUNHA, Mafalda Soares da (Org.). Do Brasil à Metrópole: efeitos sociais (séculos XVII-XVIII). Anais da Universidade de Évora, n. 8-9, p. 4772 , 2001. MONTEIRO, Nuno G. A circulação das elites no império dos Bragança (1640-1808): algumas notas. Tempo. Niterói, v. 27, p. 65-81, 2009.

8 Sobre essa questão ver ainda os trabalhos de: ROWLAND, Robert. O problema da emigração: dinâmicas e modelos. In: BETHENCOURT, Francisco; CHAUDURI, Kirti (Dir.). História da expansão portuguesa. Lisboa: Círculo dos Leitores, 1998. v. 4. SCOTT, Ana Silvia Volpi. Famílias, formas de união e reprodução social no noroeste português (séculos XVIII e XIX). Guimarães: NEPS/Universidade do Minho, 1999. RAMOS, Donald. From Minho to Minas: the portuguese roots of the Mineiro family. Hispanic American Historical Review. v. 73, nov. 1993, p. 639-662. RODRIGUES, Henrique F. Emigração e alfabetização. O Alto Minho e a miragem do Brasil. Viana do Castelo: Governo Civil de Viana do Castelo, 1995. MONTEIRO, Miguel. Mi- 
grantes, emigrantes e brasileiros (1834-1926). Fafe: NEPS/IBIT/IESF, 2000.

9 Para se ter uma ideia do tamanho de seu plantel ver: Lista de registro para cobrança dos quintos reais de 1725. Arquivo da Câmara de Mariana, códice 150.

10 Ver: COSTA, Ana Paula Pereira. Corpos de Ordenanças e chefias militares em Minas colonial: Vila Rica (1735-1777). Rio de Janeiro: FGV, 2014, 176 p.

\section{Referências}

ALMEIDA, Carla M. C. de. Homens ricos em Minas colonial. In: BICALHO, Maria Fernanda; FERLINI, Vera Lúcia do Amaral (Org.). Modos de governar. Ideias e práticas políticas no Império português, séculos XVI a XIX. São Paulo: Alameda, 2005. p. 361-384.

Uma nobreza da terra com projeto imperial: Maximiliano de Oliveira Leite e seus aparentados. In: FRAGOSO, João; ALMEIDA, Carla; SAMPAIO, Antonio Carlos Jucá de (Org.). Conquistadores e negociantes: histórias de elites no Antigo Regime nos Trópicos. América lusa, séculos XVI a XVIII. Rio de Janeiro: Civilização Brasileira, 2007. p. 121-193.

BARBOSA, Renata Bezerra de Freitas. Ler, escrever, contar, negociar : a inserção de oficiais mecânicos na cultura escrita na vila do Recife (século XVIII). In: SIMPÓSIO NACIONAL DE HISTÓRIA: CONHECIMENTO HISTÓRICO E DIÁLOGO SOCIAL, 27. 2013, Natal. Anais... Natal: UFRN, 2013. p. 1-18.

BICALHO, Maria Fernanda A cidade e o Império: o Rio de Janeiro no século XVIII. Rio de Janeiro: Civilização Brasileira, 2003.

Elites coloniais: a nobreza da terra e o governo das conquistas. História e historiografia. In: MONTEIRO, Nuno G.; CARDIM, Pedro; CUNHA, Mafalda Soares da (Org.). Optima Pars - elites ibero-americanas do Antigo Regime. Lisboa: Imprensa de Ciências Sociais, 2005. p. 73-97.
. Conquista, mercês e poder local: a nobreza da terra na América portuguesa e a cultura política do Antigo Regime. Revista Almanack Brasiliense, São Paulo, n. 2, nov. 2005.

CAMPOS, Maria verônica. Governo de mineiros. De como meter as Minas numa moenda e beber-lhe o caldo dourado. Tese (Doutorado em História) - FFLCH, USP, São Paulo, 2002.

. Goiás da década de 1730: pioneiros, elites locais, motins e fronteiras. In: BICALHO, Maria Fernanda; FERLINI, Vera Lúcia do Amaral (Org.). Modos de governar. Ideias e práticas políticas no Império português, séculos XVI a XIX. São Paulo: Alameda, 2005. p. 341-359.

COSTA, Ana Paula Pereira. Potentados locais e seu braço armado: as vantagens e dificuldades advindas do armamento de escravos na conquista das Minas. Topoi. Revista de História, Rio de Janeiro, v. 14, p. 18-32. 2013.

. Corpos de Ordenanças e chefias militares em Minas colonial: Vila Rica (1735-1777). Rio de Janeiro: FGV, 2014. 176 p.

FIGUEIREDO, Luciano R; CAMPOS, Maria Verônica (Coord.). Códice Costa Matoso. Belo Horizonte: Fundação João Pinheiro, 1999. v. 1, 2.

FONSECA, Thaís Nivia de Lima e. Letras, ofícios e bons costumes: civilidade, ordem e sociabilidade na américa portuguesa. Belo Horizonte: Autêntica, 2009. 176 p.

. Portugueses em Minas Gerais no século XVIII: cultura escrita e práticas educativas. In: ENCONTRO INTERNACIONAL DE HISTÓRIA COLONIAL. MNEME - REVISTA DE HUMANIDADES, 2. 2008. Anais... Caicó: UFRN, v. 9, n. 24, set./out. 2008. ISSN 15183394. Disponível em: <www.cerescaico.ufrn. br/mneme/anais>. Acesso em: 13 jan. 2014.

FRAGOSO, João; BICALHO, Maria Fernanda; GOUVÊA, Maria de Fátima (Org.). O Antigo Regime nos trópicos: a dinâmica imperial portuguesa (séculos XVI - XVIII). Rio de Janeiro: Civilização Brasileira, 2001. 473 p. 
FRAGOSO, João. A formação da economia colonial no Rio de Janeiro e de sua primeira elite senhorial (séculos XVI e XVII). In: FRAGOSO, João; BICALHO, Maria Fernanda; GOUVÊA, Maria de Fátima (Org.). O Antigo Regime nos trópicos: a dinâmica imperial portuguesa (séculos XVI - XVIII). Rio de Janeiro: Civilização Brasileira, 2001. p. 29-71.

Afogando em nomes temas e experiências em história econômica. Topoi. Revista de História. Rio de Janeiro, v. 5, p. 18-32. 2002.

A nobreza vive em bandos: a economia política das melhores famílias da terra do Rio de Janeiro, século XVII: algumas notas de pesquisa. Tempo, Revista do Departamento de História da UFF, Niterói, v. 15, p. 11-35. 2003.

Potentados coloniais e circuitos imperiais: notas sobre uma nobreza da terra, supracapitanias, no Setecentos. In: MONTEIRO, Nuno G.; CARDIM, Pedro; CUNHA, Mafalda Soares da (Org.). Optima Pars - elites ibero-americanas do Antigo Regime. Lisboa; Imprensa de Ciências Sociais, 2005.

. À Espera das frotas: micro história tapuia e a nobreza principal da terra (Rio de Janeiro, c.1600 - c.1750). Rio de Janeiro: UFRJ, 2005. Tese apresentada no concurso público para professor titular de Teoria da História da UFRJ.

. Capitão Manuel Pimenta Sampaio, senhor do engenho do Rio Grande, neto de conquistadores e compadre de João Soares, pardo: notas sobre uma hierarquia social costumeira (Rio de Janeiro, 1700-1760). In: FRAGOSO, João; GOUVÊA, Maria de Fátima (Org.). $\mathrm{Na}$ trama das redes. Política e negócios no império português, séculos XVI-XVIII. Rio de Janeiro: Civilização Brasileira, 2010. p. 80-88.

FRAGOSO, João; GUEDES, Roberto; KRAUSE, Thiago (Org.). A América portuguesa e os sistemas atlânticos na Época Moderna. Rio de Janeiro: FGV, 2013.
FRANCO, Francisco de Assis Carvalho. Dicionário de bandeirantes e sertanistas do Brasil. Belo Horizonte: Itatiaia; São Paulo: USP, 1989. 443 p. FURTADO, Júnia F. Homens de negócio: a interiorizarão da metrópole e do comércio nas Minas setecentistas. São Paulo: Hucitec, 1999. $289 \mathrm{p}$.

FURTADO, Júnia F. (Org.). Diálogos Oceânicos. Minas Gerais e as novas abordagens para uma história do império ultramarino português. Belo Horizonte: UFMG, 2001.

LEME, Luiz Gonzaga da Silva. Genealogia Paulistana. In: AMATO, Maria (Org.). São Paulo: Macromedia, 2002. CD.

LEME, Pedro Taques de Almeida Pais. Nobiliarquia paulistana histórica e genealógica. Belo Horizonte: Itatiaia; São Paulo: Edusp, 1980. v. 3.

MAGALHÃES, Justino. Ler e escrever no mundo rural do Antigo Regime. Braga: Universidade do Minho, 1994. 595 p.

MELLO, Evaldo Cabral de. Rubro veio: o imaginário da restauração pernambucana. Rio de Janeiro: Topbooks, 1997.

MONTEIRO, Miguel. Migrantes, emigrantes e brasileiros (1834-1926). Fafe: NEPS/IBIT/IESF, 2000.

MONTEIRO, Nuno Gonçalo. Poder senhorial, estatuto nobiliárquico e aristocracia. In: MATTOSO, José (Org.). História de Portugal: o Antigo Regime. Lisboa: Estampa, 1998. p. 297-338.

MONTEIRO, Nuno G. A circulação das elites no império dos Bragança (1640-1808): algumas notas. Revista Tempo. Niterói, v. 27, p. 65-81. 2009.

PEDREIRA, Jorge. O Brasil, fronteira de Portugal. Negócio, emigração e mobilidade social (séculos XVII e XVIII). In: CUNHA, Mafalda Soares da (Org.). Do Brasil à metrópole: efeitos sociais (séculos XVII-XVIII). Anais... da Universidade de Évora, n. 8-9, p. 47-72, 2001. 
RAMOS, Donald. From Minho to Minas: the portuguese roots of the Mineiro family. Hispanic American Historical Review. v. 73, p. 639-662. nov. 1993.

RODRIGUES, Henrique F. Emigração e alfabetização. O Alto Minho e a miragem do Brasil. Viana do Castelo: Governo Civil de Viana do Castelo, 1995.

ROMEIRO, Adriana. Paulistas e Emboabas no coração das Minas. Ideias, práticas e imaginário político no século XVIII. Belo Horizonte: UFMG, 2008. 431 p.

ROWLAND, Robert. O problema da emigração: dinâmicas e modelos. In: BETHENCOURT, Francisco; CHAUDURI, Kirti (Dir.). História da expansão portuguesa. Lisboa: Círculo dos Leitores, 1998. v. 4.

SCHOFIELD, Roger. The measurement of literacy in pre-industrial England. In: GOODY, Jack P. Literacy in traditional societies. Cambridge: Cambridge University, 1968. p. 311-325.

SCOTT, Ana Silvia Volpi. Famílias, formas de união e reprodução social no noroeste português (séculos XVIII e XIX). Guimarães: NEPS/Universidade do Minho, 1999.

SILVA, Célia Nonata da. A teia da vida: violência interpessoal nas Minas setecentistas. Dissertação (Mestrado em História) - Programa de Pós-Graduação, UFMG, Belo Horizonte, 1998.

SILVA, Francisco Ribeiro da. A alfabetização no Antigo Regime: o caso do Porto e da sua região (1580-1650). Revista da Faculdade de Letras, Lisboa, n. 3, p. 101-164. 1986.

SILVA, Maria Beatriz Nizza da. Ser Nobre na Colônia. São Paulo: Ed. Unesp, 2004.

STONE, Lawrence. Literacy and education in England, 1640-1900. Past and Present, Oxford, n. 42, p. 69-139. 1969.

VASCONCELOS, Diogo de. História antiga das Minas Gerais. Belo Horizonte: Itatiaia, 1999. $428 \mathrm{p}$.
VILLALTA, Luiz Carlos. O que se fala e o que se lê: língua, instrução e leitura. In: SOUZA, Laura de Mello e (Org.). História da vida privada no Brasil: Cotidiano e vida privada na América Portuguesa. São Paulo: Cia das Letras, 1997. p. 331-385.

. Ler, escrever, bibliotecas e estratificação social. In: RESENDE, Maria Efigênia Lage de; VILLALTA, Luiz Carlos (Org.). História de Minas Gerais. Belo Horizonte: Autêntica, 2007. p. 289-311. v. 2. 